Boise State University

ScholarWorks

7-1-2011

Perceptions of Coordination of Care Between Hospice and Skilled Nursing Facility Care Providers

Kim Martz

Boise State University

Abigail Gerding

Boise State University 


\title{
Perceptions of Coordination of Care Between Hospice and Skilled Nursing Facility Care Providers
}

\author{
Kim Martz and Abigail Gerding \\ Boise State University \\ Introduction
}

The number of older Americans who are finding Nursing Homes (NH) or Skilled Nursing Facilities (SNF) as their final place of care is increasing each year, especially the fastest growing segment of the national population who are 85 years and older ${ }^{1}$. Although the majority of older adults would prefer to die in their homes, the frailty and complexities of advanced age are leading many to the nursing home setting ${ }^{2,3}$. In 2020 , it is reported that $40 \%$ of deaths of older adults will occur in the nursing home setting ${ }^{4,5}$. Many studies have shown that NH/SNFs are not meeting the resident or families' end-of-life care needs for comfort, pain relief and emotional and spiritual support ${ }^{1}$, 6-10. Hospice care in nursing homes has been associated with decreased hospitalizations, high quality pain management and a collaborative opportunity to provide palliative care to dying residents ${ }^{11}$.

Since the Medicare legislation was adopted in 1982 allowing reimbursement of hospice care, the numbers of those accessing hospice in the long term care setting has been steadily increasing. In 2000, an estimated $16 \%$ of U.S. NH residents accessed Medicare hospice care ${ }^{12}$. By 2006, approximately $25 \%$ of Medicare hospice beneficiaries resided in $\mathrm{NH} / \mathrm{SNF}^{13}$. NH/SNF residents who were enrolled in hospice were less likely to be hospitalized in the last 6 months of life and to receive better pain management. Additionally, these residents were less likely to be restrained or have a feeding tube ${ }^{11}$.

Nursing homes and hospice both intersect and diverge from one another causing challenges in collaboration. One of the barriers to hospice care in a NH/SNF is the differences in the philosophy of care due to regulatory issues. Regulatory oversight of NH/SNF presents unique challenges to the facilities especially as the focus of hospice care is on palliative approaches instead of restorative or rehabilitative care. The focus on palliative care can impede or slow Medicaid reimbursement therefore creating financial barriers as well ${ }^{14}$. Also, the Quality Measures used by the Centers for Medicare and Medicaid Services' (CMS) do not address quality end-of-life care and can actually be in direct conflict with hospice care. For instance, the Minimum Data Set/Quality Measure surveys for NHs record issues with dehydration and weight loss and these symptoms can be part of the typical dying trajectory ${ }^{6}$. Therefore, the utilization of hospice in the NH setting brings challenges in both the clinical and policy arenas

The NH/SNF's aim is to restore and rehabilitate health while hospice's goal is to provide a holistic approach which focuses on comfort care, symptom management and emotional and spiritual support for the resident and their families in order to provide for a comfortable death. Good collaboration and understanding of these two approaches can lead to provision of quality end-of-life care in the NH/SNF setting. Collaboration between NH/SNFs and hospice agencies requires alignment of clinical goals and effective communication around residents' changing care needs $^{15}$. It is imperative to address issues of coordination, collaboration and transition for the dying nursing home resident in order that this final place of care provides the most comfortable death possible.

\section{Literature Review}

The Nursing Home Task Force of the National Hospice Organization developed a set of guidelines for hospice care in the nursing home setting in 1998 and updated in $2003{ }^{16}$. The guidelines identified the importance of communication and a coordinated plan of care. However, Parker-Oliver, revealed that more than $40 \%$ of hospice staff reported negative experiences with nursing home staff adherence to the hospice plan of care ${ }^{1}$. In this study, one third of hospice staff reported negative experiences with nursing homes regarding hospice medication ordering policies '. According to Parker-Oliver's findings, "negative experiences by hospice nurses, supervisors, and managers regarding pain management, coordination, care planning and differences in perception of philosophy of care between hospice and the nursing home setting" ${ }^{1(\mathrm{p} .71)}$ impedes the end-of-life care of the NH/SNF resident.

The Institute of Medicine's landmark report, Approaching Death, acknowledges the need for institutional accountability when applying methods of continuous quality improvement to the care of the dying. The report illustrated the need for research to better understand practice patterns and their effectiveness in the NH/SNF setting 
for hospice ${ }^{17}$. By identifying the behaviors that enhance or hinder collaborative care, both the NH/SNF and the hospice agencies can begin to accomplish better ways of communicating, implementing and standardizing the care of their dying patients.

In the Robert Wood Johnson Funded Project, "Nursing Home/Hospice Partnerships: A Model for Collaborative Success- Through Collaborative Solutions", researchers observed that successful NH/SNF and hospice partnerships resulted from well-planned efforts ${ }^{18}$. For instance, this project noted that assessing the partnership to evaluate for areas of strengths and weaknesses are key to successful collaboration in order to detect areas for quality improvement. These types of quality improvement methods such as the partnership assessment are in developmental stages in the area of end-of-life care. Moreover, research is needed to measure quality of care and correct problems at an individual or institutional level in order to improve system performance ${ }^{17}$.

Miller $^{14}$ examined NH/SNF and hospice partnerships to determine what characteristics are important for successful coordination and collaboration of care. The NH/SNF identified that successful partnerships consisted of shared values, viewed the collaboration as mutually beneficial and encouraged participation at all levels of the organizations. Critical to all of these attributes was open and frequent communication.

A recent study conducted with hospice providers indicated the barriers that impede provider relations and medication delivery include "owning" their settings; "knowing what's best for the patient"; distrust toward hospice; and emotional state. Lau and colleagues ${ }^{19}$, went on to identify additional site-readiness barriers which included communication difficulties and disagreements, responsibility overload along with differences in education and training ${ }^{19}$.

Although there are studies identifying structural and organizational barriers to quality end of life care in nursing homes 2, 15, 19, the studies surrounding the actual care processes of assessment, delivery, communication and coordination among providers and communication with residents and families are scarce ${ }^{20}$. One recent study sought to validate an instrument for measuring end-of-life care processes in nursing homes. In an effort to explore the perceptions that may influence care processes and hospice service delivery, the purpose of the present study was to explore perceptions of behaviors that contribute to collaboration between NH/SNF and hospice staff and describe the actions and behaviors of hospice and NH/SNF staff that intersect to support end-of life care of the resident in a NH/SNF.

\section{Methods}

This was an exploratory, descriptive study of perceptions of actions and behaviors of NH/SNF staff and hospice staff representing end-of-life care for patients in Skilled Nursing Facilities throughout Idaho. A Likert scale survey tool was developed using multiple existing surveys such as the City of Hope Quality Care at the End of Life Survey ${ }^{21}$, a survey of hospice providers ${ }^{1}$, and a self-assessment of clinical competency and concerns in palliative care. In addition, the collaboration questions were based on the "Nursing Home/Hospice Partnerships: A Model for Collaborative Success-Through Collaborative Solutions" $"$.

The developed tool was used to explore the similarities and differences in perceptions of nursing care between hospice and NH/SNF staff. The survey was divided into three sections. Twenty-two survey questions focused on collaboration and asked participants to rate their overall experience of working with hospice residents in a NH/SNF such as partnerships, assessment, knowledge and skills, continuity of care, pain management, spiritual needs, pastoral care, hospice support of advanced directives and hospice attendance of deaths. Fourteen survey questions asked participants to rate their overall experience of NH/SNF practices of hospice philosophy, pain assessment and management, adherence to hospice plan of care, coordination of care, benefit of hospice to the resident, identification of hospice residents and contact with hospice about changes in condition. Two questions asked participants to list benefits and barriers to care. In order to determine face validity and content validity, the survey was reviewed and evaluated by several gerontology and end-of-life care nursing experts local to the region, revisions were made and the final tool was formatted for dissemination.

After University IRB approval, data was collected from a convenience sample using the new survey tool. Demographic information of the survey participants was collected to reflect type of facility, job title and years' experience as well as where the participant worked regionally in order to detect any geographic differences. 
Surveys were initially disseminated at the Dying Well Conference, July 2009 in Boise, Idaho. One hundred and twenty-five surveys out of 200 were completed and returned during the conference. In order to have a better representation of facilities across Idaho, 200 more surveys were mailed to NH/SNFs and hospice facilities in counties and health districts not represented during initial dissemination. Seventy-five additional surveys were returned for a total of 200 surveys.

Data were analyzed using descriptive statistics and frequencies to determine similarities and differences related to collaboration, care for hospice clients in NH/SNFs, and barriers and benefits to EOL care. Since the survey tool used a Likert scale for determining perceptions of behaviors, chi-square was employed to determine if significant differences occurred between the groups, hospice providers and NH/SNF providers. A chi square $\left(x^{2}\right)$ statistic was used to investigate whether distributions of categorical variables differ from one another. Scores from the scaled items were summed and t-tests were employed to determine differences between hospice and NH/SNF providers as well as to determine the direction of the responses.

Reliability scores indicated the tool had internal consistency (Cronbach alpha= 0.858). Subcategories of the tool measuring collaboration and care for hospice clients in a NH/SNF also indicated internal consistency using Cronbach alpha (0.819). Measuring the subcategory of collaboration achieved a Cronbach alpha of 0.862 and the subcategory of care for hospice clients in a NH/SNF achieved a Cronbach alpha of 0.929. This indicated that the tool was reliable and maintained internal consistency in measuring the perceptions of hospice and NH/SNF providers related to collaboration and care for hospice clients in a NH/SNF.

\section{Results}

Surveys were returned by 200 hospice and NH/SNF providers representing 30 of 44 Idaho counties and all 7 health districts in Idaho. Ninety-five hospice providers and $91 \mathrm{NH} / \mathrm{SNF}$ providers returned surveys. As expected the largest group of providers was RNs (29.5\%). The second largest group of participants was social workers (15.3\%) and CNAs were the third largest group (11.6\%). (Figure 1).

\section{Demographics}

The 200 returned surveys were collected from the conference and mailings. In order to determine differences between surveys returned at the conference and surveys returned from the mailings, descriptive statistics were employed. From the surveys received during the conference, 45 hospice staff and $77 \mathrm{NH} / \mathrm{SNF}$ staff were represented. The surveys retuned via mail represented 50 hospice staff and $14 \mathrm{NH} / \mathrm{SNF}$ staff and one other. Ten mailed surveys did not indicate their position title.

The range of years of experience in skilled nursing was from 1 to 48 years with the largest percentage $(80 \%)$ between 1 and 20 years. The range of years of experience in hospice was from less than a year to 29 years with the largest percentage $(85 \%)$ having between 1 and 10 years of experience. The mean number of years in skilled nursing was 14.2 years and the mean number of years in hospice was 6 years. There were no significant differences in years of experience in skilled nursing between mailed surveys and those received at the conference.

Ninety-five hospice staff and $91 \mathrm{NH} / \mathrm{SNF}$ staff were represented, demonstrating a fairly even distribution between hospice and NH/SNF staff across facilities. Of the 95 hospice providers who returned the survey, 94 have had hospice patients in a NH/SNF and of the $91 \mathrm{NH} / \mathrm{SNF}$ providers who returned the survey, 81 have had hospice patients in their facility. Since the goal of the study was to explore similarities and differences across NH/SNF and hospice staff who had cared for a hospice patient in a NH/SNF, those providers who did not care for a hospice patient in a NH/SNF were eliminated. The remaining 175 surveys were used to examine the data.

\section{Collaboration}

To measure collaboration, a Likert scale was used to rate the experience of the providers from Always (1) to Never (4) and Unknown (5). Using chi-square to determine differences between group answers, hospice and NH/SNF staff both demonstrated that partnerships and positive staff relationships result from effective planning, indicating the willingness to work to together. Both hospice and NH/SNF staff felt they had necessary knowledge and skills required to care for dying patients, there is effective continuity of care, pain is effectively assessed and managed as well as family meetings are conducted in a timely manner. However, significant differences did exist when asked if 
mechanisms were in place to facilitate regular assessment of the partnerships. Thirty-eight percent of hospice providers always or usually experience regular assessment of partnerships compared to $26 \%$ of NH/SNF staff experienced regular assessment of partnerships $\left(\mathrm{x}^{2}(4)=17.883, \mathrm{p}<0.001\right)$. Forty-five percent of hospice providers stated that always or usually assessment is used to identify people at risk for grief and bereavement while only $33 \%$ of NH/SNF providers experienced this always or usually $\left(\mathrm{x}^{2}(4)=28.646, \mathrm{p}<0.001\right)$. Forty-three percent $(43 \%)$ of hospice providers indicated that they always or usually experienced staff as knowledgeable and sensitive to diverse religious or spiritual needs, while only $36 \%$ of NH/SNF providers indicated that they experienced such care $\left(\mathrm{x}^{2}\right.$ $(4)=14.940, p=0.005)$. Fifty percent of hospice providers indicated pastoral care available and effective always or usually, while $35 \% \mathrm{NH} / \mathrm{SNF}$ providers experienced this $\left(\mathrm{x}^{2}(4)=23.656, \mathrm{p}=0.001\right)$. Forty-nine percent of hospice providers reported belief that hospice supported the NH/SNF in facilitating the resident's advance directive decisions always or usually, while $30 \%$ of NH/SNF providers experienced this always or usually $\left(x^{2}(4)=25.527\right.$, $\mathrm{p}<0.001)$. Forty-seven percent of hospice providers reported that someone from hospice attended the deaths of patients always or usually while, only $16 \%$ of NH/SNF providers reported this behavior as always or usually $\left(x^{2}\right.$ $(4)=59.088, p<0.001)($ Table 1).

\section{Collaboration Benefits}

There was no significant difference between hospice and NH/SNF providers' ability to appropriately identify hospice patients. Significant differences did occur when rating whether hospice was a benefit to NH/SNF residents, rating the effectiveness of hospice education programs in NH/SNFs, and communication with hospice and NH/SNF staff. Fifty-one percent of hospice providers rated the benefit of hospice to a NH/SNF resident as positive to most positive while only $22 \%$ of $\mathrm{NH} / \mathrm{SNF}$ providers rated the benefit as positive to most positive. Twenty-five percent of hospice providers rated the effectiveness of hospice education programs in NH/SNF positive to most positive, while only $11 \%$ of NH/SNF providers rated the effectiveness positive to most positive. Thirty-three percent of hospice providers rated communication with hospice/NH/SNF as most positive while only $16 \%$ of NH/SNF providers rated most positive (Table 2).

\section{Hospice and NH/SNF Perceptions of Hospice Care in a NH/SNF}

Hospice and NH/SNF providers were asked to respond to statements on a 5 point Likert scale from worst (1) to best (5) related to their overall experience of how NH/SNF staff worked with designated hospice patients in a NH/SNF. Responses were summed and then crosstabs and t-tests were used to examine differences and similarities between hospice providers and NH/SNF providers (Table 3). Hospice and NH/SNF providers indicated that NH/SNF staff does a good job of contacting the hospice agency with problems or changes in the resident's condition. NH/SNF providers rated their ability to assess pain, use needed pain medication and have a good knowledge of pain management as good to best in a range of thirty-three to thirty-eight percent, with only $17 \%-22 \%$ of hospice providers demonstrating these ratings. Twenty-one percent of NH/SNF providers rated their understanding of hospice philosophy as good to best but only $16 \%$ of hospice providers rated NH/SNF understanding of hospice philosophy as good to best. Although the means indicated a significant difference ( $3.28 \& 3.76 ; \mathrm{p}<.001)$ between hospice and NH/SNF providers when rating NH/SNF staff adherence to the hospice care plan, $24 \%$ of hospice staff and $28 \%$ of NH/SNF staff rated NH/SNF adherence to the care plan as good to best. When rating the NH/SNF staff understanding of hospice regulations, $23 \%$ of hospice providers rated NH/SNF staff as bad to worst while only $11 \%$ of NH/SNF providers rated their understanding of hospice regulations as bad to worst.

When examining coordination of care, $19 \%$ of hospice providers rated NH/SNF coordination efforts as good to best, compared to $25 \%$ of NH/SNF staff. Both providers recognize a discrepancy in coordination efforts. However, $32 \%$ of NH/SNF providers rated their ability to identify hospice patients as good to best, compared to $18 \%$ of hospice providers. This difference substantiates a continued demonstration of a lack of communication between providers. One of the largest differences was demonstrated when asked to rate the benefit of hospice to a NH/SNF resident. Only $15 \%$ of NH/SNF providers rated this good to best, compared to almost half (47\%) of the hospice providers (Table 3). 


\section{Discussion}

The findings indicated discrepancies in health care providers' perceptions of the philosophy of care and coordination of care between hospice and the NH/SNF setting. Both agencies intersected in their recognition of areas that are problematic. The differences in the regulations and communication difficulties of these facilities appear to be the greatest barriers of collaboration in quality end of life care.

\section{Collaboration}

Although both hospice staff and NH/SNF staff indicated that collaboration was important to the care of a hospice resident, there were variations in the perception of hospice care in the area of collaboration. Hospice perceptions of their own services to the nursing home were positive, while the NH/SNF staff did not perceive hospice services as always positive. This could be due to the juxtaposing care philosophies or that NH/SNF staff do not perceive hospice as a benefit to the resident as indicated by the study. NH/SNF staff provides restorative or rehabilitative care to the frail elderly as part of their normal care. The misalignment of goals of care and the lack of coordinated efforts to address the resident needs may play a role in the lack of positive perceptions of hospice care by NH/SNF staff. NH/SNF did not feel that there was always or usually assessment of complicated grief, or that there was always pastoral care available and effective. The most significant perception of hospice staff was that someone from hospice attended the deaths of hospice patients in the NH/SNF. Nearly half of hospice reported they attended the death of a resident while only $17 \% \mathrm{NH} / \mathrm{SNF}$ staff reported attendance occurs. This denotes a large variation in the perceptions of occurrence of this intervention between hospice and NH/SNF staff. Also, the role of hospice to attend the death may not be communicated effectively. There is no indication as to why this perception occurs, although since communication is reported throughout the study to be an issue it may be that there is little to no communication surrounding this intervention.

Hospice and NH/SNF had similar responses related to their ability to appropriately identify hospice patients. They differed on their responses related to the benefit of hospice for a NH/SNF resident. Since both staff felt they had knowledge and skills to work with a hospice resident, it may be that NH/SNF staff viewed the complexity of adding hospice to their already complex care issues a burden ${ }^{19}$. In addition, many residents become like family members to $\mathrm{NH} / \mathrm{SNF}$ staff and the initiation of hospice care may cause territorial issues due to their ownership of the resident's care. Also, it may indicate the NH/SNF staff feels that this care is already being delivered in their environment and hospice is seen as a duplication of their services while NH/SNF staff must continue to provide an acceptable level of personal care unrelated to terminal care ${ }^{22}$. These differences in care goals may present continued challenges to the NH/SNF staff.

The addition of hospice care as a burden may also be reflected in the perception of communication and pain management. Hospice perceived communication as more positive than NH/SNF reported, indicating differences in perceptions of these two providers. In a number of studies, NH/SNFs perception was that their staff provided adequate end-of-life care and did not need hospice support ${ }^{7,15,19}$. The present study supported this finding as the $\mathrm{NH} / \mathrm{SNF}$ staff rated higher than hospice in all areas of care. However, other studies indicated that hospice patients in a nursing facility are more likely to have their pain assessed and receive better pain management, along with emotional and spiritual support and less hospitalizations when attended by hospice staff ${ }^{11}$.

\section{NH/SNF and Hospice practices}

Although communication was identified throughout the study as problematic, one level of intersection was the $\mathrm{NH} / \mathrm{SNF}$ contact with hospice to report changes in conditions or problems with the resident. Although this indicated they may be communicating about changes in the resident, it does not indicate whether their clinical goals align which would indicate effective collaboration ${ }^{15}$. Miller determined that communication was key in successful partnerships, however without alignment of shared values and goals effective collaboration may be difficult ${ }^{14}$.

Both providers agreed that NH/SNFs' understanding of hospice regulations were mediocre. As one study noted, both of these providers must comply with not only different regulations and reimbursement systems, but in addition they have very different levels of autonomy in their practices ${ }^{23}$. One example of regulations differences concerns the use of "as needed" medication. NH/SNF felt that their use of "as needed" medication for pain was adequate while over half of the hospice staff reported it mediocre to poor. This may again be a communication issue between hospice staff, the resident and the NH/SNF. Each agency must be clear about their clinical responsibilities ${ }^{15}$. 
Hospice has a greater focus on pain management and would assess for as needed medication, whereas the NH/SNF are more focused on routine medications. In a recent study on the barriers to effective medication delivery, researchers identified attitudinal barriers of "knowing what's best for the patients", along with differences in care priority and in education and training ${ }^{19}$. One study identified that NH/SNF staff were not willing to give "as needed" pain meds if the patient was not able to verbalize needs ${ }^{24}$. Hospice philosophy is to provide pain management at regular intervals. The differences in pain management interventions could be a divergence between regulations and philosophies. These care processes along with conflicts among care providers, may have an adverse impact on residents medication delivery and symptom management in hospice service delivery ${ }^{19}$.

\section{Limitations}

Limitations of this study include: 1) no data related to size of hospice facilities or NH/SNF is represented in this study, 2) there was limited data from geographic areas which did not allow for statistical comparisons and 3) although the survey tool indicated reliability (Cronbach alpha $=0.858$ ), there may have been issues with utilizing the same survey for both hospice and NH/SNF staff.

\section{Implications}

The findings from this study indicated perceived barriers to quality end-of-life care with differences in hospice and $\mathrm{NH} / \mathrm{SNF}$ regulations, communication and collaboration. This study is consistent with other studies indicating the need to continue to educate skilled nursing facility staff in an effort to improve care for all residents $7,11,15,17,24$. Education should revolve around regulations, philosophies of care, and palliative care. Also, Miller found that although formal education opportunities were significant to successful partnerships, informal one-on-one educational opportunities between hospice and NH/SNF staff aided their knowledge of skills, philosophies and beliefs ${ }^{14}$. Creating opportunities for interaction between hospice and NH/SNF staff is essential in building a cohesive, collaborative team.

Participants indicated that communication was a barrier to end-of-life care. As beliefs are shared and more familiarity with regulations and care issues occur, protocols could be developed focused on communication, integrated assessment and coordination efforts. Specialty teams and end-of-life dedicated teams need to be evaluated for benefit and enhancement of end-of-life care for the dying NH/SNF resident. In 2004, 19\% of U.S. NH/SNFs had special programs and/or trained staff (SPTS) for hospice with 17\% of NH/SNF having SPTS for palliative/end-of-life care. NH/SNF with SPTS were more likely to have coordinated efforts with hospice facilities 10. The development of SPTS and/or dedicated teams could lead to more effective assessments and treatment strategies for NH/SNF residents needing hospice and/or palliative/end-of-life care. Team building efforts could help to build trust, improve shared decision-making and help to address the issues of "ownership" of the care ${ }^{19}$.

Miller determined that successful partnerships begin with chief executive officers (CEO) from both hospice and NH/SNFs, with hospice CEOs appearing to be the driving force in the development of successful partnerships ${ }^{14}$. It may be of benefit to find ways to gather CEOs from hospice and NH/SNFs to verbalize philosophies and missions in order to find pathways that will support the needs of the NH/SNF while meeting the end-of-life needs of the NH/SNF resident.

The present study suggests that the collaboration between NH/SNF and hospice is dependent on a coordinated plan of care. The findings revealed that the regulations are extremely conflicting and have implications and changes in policy are necessary. There is a need for future research to compile data which identifies issues of cost, service intensity and quality of care for the Medicare hospice benefit ${ }^{15}$.

\section{Conclusions}

The fastest growing segment of the US population is 85 years and older and many in this vulnerable population are finding NH/SNF as their final place of care. Once admitted, the majority of residents' length of stay is less than six months ${ }^{25}$. The provision of hospice care in the Skilled Nursing Facility provides benefits such as reduced hospitalizations, better assessment and management of pain as well as family and spiritual support for dying residents $4,11,15,17,18,22,24,26$. This study supports the need for collaboration for quality end-of-life care. Nursing has an opportunity to provide the leadership necessary to improve practices and collaboration through well planned efforts of communication and education of both providers regarding the regulations and standards of care. 


\section{References}

1. Parker-Oliver D. Hospice experience and perceptions in Nursing Homes. Journal of Palliative Medicine. 2002; 5(5):713-719.

2. Hanson LC, Sengupta S, Slubicki M. Access to Nursing Home Hospice: Perspectives of Nursing Home and Hospice Administrators. Journal of Palliative Medicine 2005; 8(6):1207-1213.

3. Leishman J. Older People: Death, cying and end of life care. . Quality in Ageing. 2008; 9(4):36-43.

4. $\quad$ Brown University. Atlas Site of Death 1989-1997 2000.

5. Katz BP, Zdeb MS, Therriault GD. Where people die. Public Health Reports. 1979; 94:522-527.

6. Huskamp HA, Stevenson DG, Chernew ME, Newhouse JP. A New Medicare End-of-Life Benefit for Nursing Home Residents. Health Affairs. 2010; 29(1):130-135.

7. Tarzian AH, D. A Statewide Survey Identifying Perceived Barriers to Hospice Use in Nursing Homes. Journal of Hospice and Palliative Nursing. 2006; 8(6).

8. Miller SC, Mor V. The opportunity for collaborative care provision:The presence of nursinghome/hospice collaborations in the U.S. states. . Journal of Pain and Symptom Management 2004; 28(6):537-546.

9. Cassaret D, Karlawish J, Morales K, Crowley R, Mirsch T, \& Asch D. Improving the use of hospice services in nursing home: A randomized controlled trial. JAMA. 2005; 294(2):211-217.

10. Miller SC, Han, B. End-of-Life Care in U.S. Nursing Homes: Nursing Homes with Special Programs and Trained Staff for Hospice or Palliative /End-of-Life Care. Jouranl of Palliative Medicine. 2008; 11(6):866877.

11. Miller SC, Mor V, Wu N, Gozalo P, Lapane K. Does receipt of hospice care in nursing homes improve the management of pain at the end of life? Journal of the American Geriatrics Society. 2002; 50(3):507-515.

12. Gozalo P, Miller SC. Hospice enrollment and evaluation of its causal effect on hospitalization of dying nursing home patients. Health Services Research. 2007; 42(2):587-610.

13. Miller SC, Lima J, Gozalo PL, Mor V. The Growth of Hospice Care in the U.S. Nursing Homes. Journal of American Geriatrics. 2010; 58(8):1481-1488.

14. Miller SC. A Model for Successful Nursing Home-Hospice Parnerships. Journal of Palliative Medicine. 2010; 13(5):525-533.

15. Stevenson DG, Bramson JS. Hospice care in the nursing home setting: A review of the literature. Journal of Pain and Symptom Management. 2009; 38(3):440-451.

16. National Hospice and Palliative Care. Hospice Care in Nursing Facilities: An Educational Resource for Effective Partnerships in End-of-Life Care September 6, 20102001.

17. Approaching Death: IMPROVING CARE AT THE END OF LIFE: National Academy Press: Washington D.C.; 1998.

18. Miller SC. Nursing home/hospice partnerships:A model for collaborative success-through collaborative solutions. A Report Funded through the Robert Wood Johnson Foundation: Brown University Medical School; 2007.

19. Lau DT, Masin-Peters J, Berdes C, Ong M. Perceived Barriers that Impede Provider Relations and Medication Delivery: Hospice Providers' Experiences in Nursing Homes and Private Homes. Journal of Palliative Medicine. 2010; 13(3):305-310.

20. Temkin-Greener H, Zheng N, Norton SA, Quill T, Ladwig S, Vezie P. Measuring End-of-Life Care Processes in Nursing Homes. The Gerontologist. 2009; 49(6):803-815.

21. Quality Care at the End of Life Survey: City of Hope Pain \& Palliative Care Resource Center; n.d.

22. Zerzan J, Sterns S, Hanson L. Access to palliative care and hospice in nursing homes. JAMA. 2000; 284(19):2489-2494.

23. Keay TJ, Schonwetter RS. The case for hospice care in long-term care environments. Clinics in Geriatric Medicine. 2000; 16(2):211-213.

24. Parker-Oliver D, Porock D, Zweigh S. End-of-life care in U.S. nursing homes:A review of the evidence. Journal of American Medical Directors Association. 2004; 5(3):147-155.

25. Kelly A, Conell-Price J, Covinsky K, Genzer, I., Chang A, Boscardin W, Smith A. Length of stay for older adults residing in nursing homes at the end of life. Journal of American Geriatric Society. 2010; 58(9):1701-1706.

26. Solomon M. Institutional accountability in end-of-life care: Organzational leadership, measurement, and consumer demand. Journal of Palliative Medicine. 2000; 3(2):225-228. 
Figure 1: Positions of participants

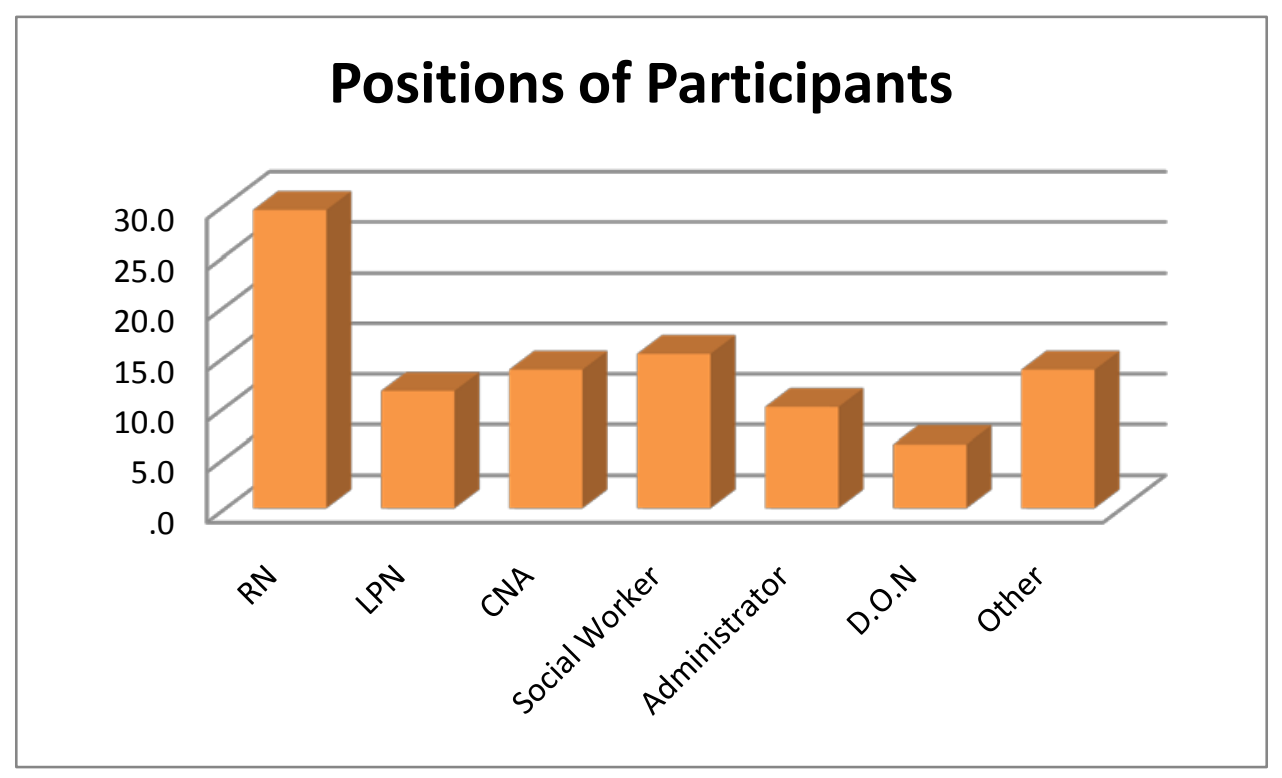


Table 1: Hospice \& NH/SNF staff perceptions of Collaboration using Chi-Square

\begin{tabular}{|c|c|c|c|c|c|c|}
\hline & $\begin{array}{l}\text { Type of } \\
\text { Provider }\end{array}$ & $\begin{array}{c}\text { Always } \\
1\end{array}$ & $\begin{array}{l}\text { Usually } \\
2\end{array}$ & $\begin{array}{c}\text { Occasionally } \\
3\end{array}$ & $\begin{array}{c}\text { Never } \\
4\end{array}$ & $\begin{array}{c}\text { Unknown } \\
5\end{array}$ \\
\hline \multirow{2}{*}{$\begin{array}{l}\text { Partnerships and positive staff } \\
\text { relationships (at all levels) result } \\
\text { from effective planning. }\end{array}$} & $\begin{array}{l}\text { Hospice } \\
\text { Provider }\end{array}$ & $18.0 \%$ & $30.0 \%$ & $5 \%$ & $.0 \%$ & $.6 \%$ \\
\hline & $\begin{array}{l}\mathrm{NH} / \mathrm{SNF} \\
\text { Provider }\end{array}$ & $11.2 \%$ & $28.4 \%$ & $5 \%$ & $.6 \%$ & $.6 \%$ \\
\hline \multirow{2}{*}{$\begin{array}{l}\text { Mechanisms are in place to } \\
\text { facilitate regular assessment of } \\
\text { the partnerships between NH/SNF } \\
\& \text { hospice. } \\
(\times 2(4)=17.883, p<0.001)\end{array}$} & $\begin{array}{l}\text { Hospice } \\
\text { Provider }\end{array}$ & $14 \%$ & $24 \%$ & $14 \%$ & $1.2 \%$ & $1.2 \%$ \\
\hline & $\begin{array}{l}\text { NH/SNF } \\
\text { Provider }\end{array}$ & $4.2 \%$ & $21.4 \%$ & $9.5 \%$ & $6 \%$ & $4.0 \%$ \\
\hline \multirow{2}{*}{$\begin{array}{l}\text { Staff has the necessary } \\
\text { knowledge and skills required to } \\
\text { care for dying residents and their } \\
\text { families. }\end{array}$} & $\begin{array}{l}\text { Hospice } \\
\text { Provider }\end{array}$ & $22 \%$ & $22 \%$ & $9.4 \%$ & $.0 \%$ & $.0 \%$ \\
\hline & $\begin{array}{l}\text { NH/SNF } \\
\text { Provider }\end{array}$ & $12.3 \%$ & $26.3 \%$ & $7 \%$ & $.0 \%$ & $.1 \%$ \\
\hline \multirow[t]{2}{*}{$\begin{array}{l}\text { There is effective continuity of } \\
\text { care between NH/SNF \& hospice. }\end{array}$} & $\begin{array}{l}\text { Hospice } \\
\text { Provider }\end{array}$ & $11.7 \%$ & $29.2 \%$ & $14 \%$ & $.0 \%$ & $.0 \%$ \\
\hline & $\begin{array}{l}\text { NH/SNF } \\
\text { Provider }\end{array}$ & $6.4 \%$ & $26.9 \%$ & $10.5 \%$ & $1.2 \%$ & $.0 \%$ \\
\hline \multirow[t]{2}{*}{$\begin{array}{l}\text { Pain is effectively assessed and } \\
\text { managed. }\end{array}$} & $\begin{array}{l}\text { Hospice } \\
\text { Provider }\end{array}$ & $19.9 \%$ & $28.1 \%$ & $5.8 \%$ & $.0 \%$ & $.0 \%$ \\
\hline & $\begin{array}{l}\mathrm{NH} / \mathrm{SNF} \\
\text { Provider }\end{array}$ & $19.3 \%$ & $23.4 \%$ & $2.3 \%$ & $.6 \%$ & $.6 \%$ \\
\hline \multirow{2}{*}{$\begin{array}{l}\text { Assessment is used to identify } \\
\text { people at risk for complicated } \\
\text { grief and bereavement. } \\
(x 2(4)=28.646, p<0.001)\end{array}$} & $\begin{array}{l}\text { Hospice } \\
\text { Provider }\end{array}$ & $32 \%$ & $13.4 \%$ & $5.8 \%$ & $2.3 \%$ & $.6 \%$ \\
\hline & $\begin{array}{l}\text { NH/SNF } \\
\text { Provider }\end{array}$ & $9.9 \%$ & $23.3 \%$ & $5.2 \%$ & $3.5 \%$ & $4.1 \%$ \\
\hline
\end{tabular}




\begin{tabular}{|c|c|c|c|c|c|c|}
\hline \multirow{2}{*}{$\begin{array}{l}\text { Family meetings are conducted in } \\
\text { a timely manner to provide } \\
\text { information, assist in decision- } \\
\text { making and determine wishes. }\end{array}$} & $\begin{array}{l}\text { Hospice } \\
\text { Provider }\end{array}$ & $20.3 \%$ & $26.7 \%$ & $6.4 \%$ & $.0 \%$ & $.6 \%$ \\
\hline & $\begin{array}{l}\text { NH/SNF } \\
\text { Provider }\end{array}$ & $14 \%$ & $22.7 \%$ & $6.4 \%$ & $.6 \%$ & $2.3 \%$ \\
\hline \multirow{2}{*}{$\begin{array}{l}\text { Staff is knowledgeable and } \\
\text { sensitive to diverse } \\
\text { religious/spiritual needs. } * \\
(x 2(4)=14.940, p=0.005)\end{array}$} & $\begin{array}{l}\text { Hospice } \\
\text { Provider }\end{array}$ & $22.8 \%$ & $20.5 \%$ & $9.4 \%$ & $.6 \%$ & $1.2 \%$ \\
\hline & $\begin{array}{l}\text { NH/SNF } \\
\text { Provider }\end{array}$ & $7.6 \%$ & $28.1 \%$ & $7 \%$ & $1.2 \%$ & $1.8 \%$ \\
\hline \multirow[t]{2}{*}{$\begin{array}{l}\text { Pastoral care/chaplaincy is } \\
\text { available and effective. } \\
(\times 2(4)=23.656, p=0.001)\end{array}$} & $\begin{array}{l}\text { Hospice } \\
\text { Provider }\end{array}$ & $33.3 \%$ & $17.5 \%$ & $2.9 \%$ & $.0 \%$ & $.6 \%$ \\
\hline & $\begin{array}{l}\text { NH/SNF } \\
\text { Provider }\end{array}$ & $12.3 \%$ & $23.8 \%$ & $8.8 \%$ & $1.2 \%$ & $.6 \%$ \\
\hline \multirow{2}{*}{$\begin{array}{l}\text { Hospice supported the NH/SNF in } \\
\text { facilitating the resident's advance } \\
\text { directive decisions.* } \\
(x 2(4)=25.527, p<0.001)\end{array}$} & $\begin{array}{l}\text { Hospice } \\
\text { Provider }\end{array}$ & $30 \%$ & $19.4 \%$ & $3.5 \%$ & $.0 \%$ & $2.4 \%$ \\
\hline & $\begin{array}{l}\text { NH/SNF } \\
\text { Provider }\end{array}$ & $9.4 \%$ & $20.6 \%$ & $6.5 \%$ & $3.5 \%$ & $4.7 \%$ \\
\hline \multirow{2}{*}{$\begin{array}{l}\text { Someone from hospice attends } \\
\text { the deaths of hospice patients in } \\
\text { your NH/SNF.* } \\
(x 2(4)=59.088, p<0.001)\end{array}$} & $\begin{array}{l}\text { Hospice } \\
\text { Provider }\end{array}$ & $24.3 \%$ & $23.1 \%$ & $4.1 \%$ & $.6 \%$ & $2.4 \%$ \\
\hline & $\begin{array}{l}\text { NH/SNF } \\
\text { Provider }\end{array}$ & $2.4 \%$ & $13.6 \%$ & $21.3 \%$ & $4.7 \%$ & $3.6 \%$ \\
\hline
\end{tabular}

*denotes significance with $p \leq 0.005$ 
Table 2: Collaboration Benefits using T-Test

\begin{tabular}{|c|c|c|c|c|c|c|c|c|}
\hline & $\begin{array}{l}\text { Type of } \\
\text { Provider }\end{array}$ & $\mathbf{N}$ & Mean & $\begin{array}{c}\text { Std. } \\
\text { Deviation }\end{array}$ & $\begin{array}{c}\text { Least } \\
\text { Positive }\end{array}$ & 2 & 3 & $\begin{array}{c}\text { Positive/Most } \\
\text { Positive }\end{array}$ \\
\hline \multirow{2}{*}{$\begin{array}{l}\text { Benefit of } \\
\text { Hospice to } \\
\text { NH/SNF } \\
\text { resident* }\end{array}$} & Hospice & 94 & 4.60 & .859 & $1.7 \%$ & $.6 \%$ & $1.2 \%$ & $51 \%$ \\
\hline & $\mathrm{NH} / \mathrm{SNF}$ & 79 & 3.35 & 1.050 & $3.5 \%$ & $4.0 \%$ & $16.2 \%$ & $22 \%$ \\
\hline \multirow{2}{*}{$\begin{array}{l}\text { Ability to ID } \\
\text { Hospice Pts }\end{array}$} & Hospice & 94 & 3.67 & 1.121 & $2.9 \%$ & $5.2 \%$ & $12.7 \%$ & $33 \%$ \\
\hline & $\mathrm{NH} / \mathrm{SNF}$ & 79 & 3.59 & .855 & $.0 \%$ & $5.2 \%$ & $13.9 \%$ & $26 \%$ \\
\hline \multirow{2}{*}{$\begin{array}{l}\text { Effectiveness of } \\
\text { Hospice Ed in } \\
\text { NH/SNFs* }\end{array}$} & Hospice & 93 & 3.39 & .989 & $2.3 \%$ & $5.8 \%$ & $21.6 \%$ & $25 \%$ \\
\hline & $\mathrm{NH} / \mathrm{SNF}$ & 78 & 2.91 & .914 & $3.5 \%$ & $9.4 \%$ & $21.6 \%$ & $11 \%$ \\
\hline \multirow{2}{*}{$\begin{array}{l}\text { Communication } \\
\text { with hospice \& } \\
\text { NH/SNF Staff* }\end{array}$} & Hospice & 94 & 3.68 & .918 & $1.2 \%$ & $3.5 \%$ & $16.9 \%$ & $33 \%$ \\
\hline & $\mathrm{NH} / \mathrm{SNF}$ & 78 & 3.15 & .884 & $1.7 \%$ & $7.6 \%$ & $19.8 \%$ & $16 \%$ \\
\hline
\end{tabular}

*denotes significance with $p \leq 0.001$ 
Table 3: SNF/NH and Hospice staff ratings of practice by T-Test

\begin{tabular}{|c|c|c|c|c|c|c|c|c|}
\hline & & Mean & SD & Worst & 2 & 3 & 4 & Best \\
\hline \multirow{2}{*}{$\begin{array}{l}\text { SNF/NH practice of hospice } \\
\text { philosophy* }\end{array}$} & HOSPICE & 2.97 & 0.938 & $3.0 \%$ & $13.7 \%$ & $23.2 \%$ & $13.1 \%$ & $2.4 \%$ \\
\hline & SNF/NH & 3.49 & 0.760 & $0.0 \%$ & $3.0 \%$ & $20.8 \%$ & $16.7 \%$ & $4.2 \%$ \\
\hline \multirow{2}{*}{ Assessment of pain* } & HOSPICE & 3.16 & 1.009 & $2.4 \%$ & $12.6 \%$ & $18.0 \%$ & $18.0 \%$ & $4.2 \%$ \\
\hline & SNF/NH & 3.92 & 0.784 & $0.0 \%$ & $1.8 \%$ & $10.2 \%$ & $2208.0 \%$ & $10.2 \%$ \\
\hline \multirow[t]{2}{*}{ Adherence to hospice care plan* } & HOSPICE & 3.28 & 0.887 & $0.6 \%$ & $10.5 \%$ & $21.0 \%$ & $19.8 \%$ & $3.7 \%$ \\
\hline & SNF/NH & 3.76 & 0.831 & $0.0 \%$ & $2.5 \%$ & $14.2 \%$ & $19.1 \%$ & $8.6 \%$ \\
\hline \multirow{2}{*}{ Use of medication for pain* } & HOSPICE & 3.20 & 0.984 & $1.2 \%$ & $13.0 \%$ & $19.5 \%$ & $16.0 \%$ & $5.3 \%$ \\
\hline & SNF/NH & 3.97 & 0.765 & $0.0 \%$ & $1.2 \%$ & $10.1 \%$ & $22.5 \%$ & $11.2 \%$ \\
\hline \multirow[t]{2}{*}{ Knowledge of pain management* } & HOSPICE & 3.10 & 0.979 & $2.4 \%$ & $11.9 \%$ & $23.8 \%$ & $12.5 \%$ & $4.8 \%$ \\
\hline & SNF/NH & 3.91 & 0.873 & $0.6 \%$ & $2.4 \%$ & $8.3 \%$ & $22.6 \%$ & $10.7 \%$ \\
\hline \multirow{2}{*}{$\begin{array}{l}\text { Adherence to hospice medication } \\
\text { order policies* }\end{array}$} & & 3.46 & 0.965 & $0.6 \%$ & $9.0 \%$ & $18.0 \%$ & $19.8 \%$ & $7.8 \%$ \\
\hline & SNF/NH & 3.95 & 0.804 & $0.0 \%$ & $1.8 \%$ & $10.2 \%$ & $21.6 \%$ & $11.4 \%$ \\
\hline \multirow{3}{*}{$\begin{array}{l}\text { Adherence to hospice care plan as it } \\
\text { pertains to feeding, dietary and } \\
\text { intake* }\end{array}$} & HOSPICE & & & & & & & \\
\hline & & 3.31 & 1.021 & $1.8 \%$ & $9.6 \%$ & $21.6 \%$ & $15.0 \%$ & $7.8 \%$ \\
\hline & SNF/NH & 3.84 & 0.844 & $0.0 \%$ & $3.0 \%$ & $10.8 \%$ & $21.0 \%$ & $9.6 \%$ \\
\hline \multirow{3}{*}{$\begin{array}{l}\text { Contact hospice agency with } \\
\text { changes in condition or problems } \\
\text { with resident }\end{array}$} & HOSPICE & & & & & & & \\
\hline & & 3.47 & 0.996 & $1.8 \%$ & $5.3 \%$ & $22.5 \%$ & $16.0 \%$ & $9.5 \%$ \\
\hline & SNF/NH & 3.70 & 0.910 & $0.6 \%$ & $3.6 \%$ & $13.0 \%$ & $19.5 \%$ & $8.3 \%$ \\
\hline \multirow{2}{*}{$\begin{array}{l}\text { Understanding of hospice } \\
\text { regulations* }\end{array}$} & HOSPICE & 2.76 & 0.993 & $4.8 \%$ & $18.5 \%$ & $19.6 \%$ & $10.1 \%$ & $2.4 \%$ \\
\hline & SNF/NH & 3.15 & 0.982 & $2.4 \%$ & $8.9 \%$ & $15.5 \%$ & $15.5 \%$ & $2.4 \%$ \\
\hline
\end{tabular}




\begin{tabular}{|c|c|c|c|c|c|c|c|c|}
\hline & & Mean & SD & Worst & 2 & 3 & 4 & Best \\
\hline \multirow{2}{*}{$\begin{array}{l}\text { Appropriate use of OT, ST, PT } \\
\text { with hospice patients* }\end{array}$} & HOSPICE & 3.02 & 1.060 & $3.0 \%$ & $15.9 \%$ & $17.7 \%$ & $13.4 \%$ & $4.9 \%$ \\
\hline & SNF/NH & 3.39 & 0.963 & $0.0 \%$ & $8.5 \%$ & $17.7 \%$ & $12.8 \%$ & $6.7 \%$ \\
\hline \multirow{2}{*}{$\begin{array}{l}\text { Coordination efforts for } \\
\text { hospice patients }\end{array}$} & HOSPICE & 3.16 & 0.929 & $1.8 \%$ & $10.1 \%$ & $24.4 \%$ & $14.3 \%$ & $4.2 \%$ \\
\hline & SNF/NH & 3.53 & 0.871 & $1.2 \%$ & $3.0 \%$ & $16.7 \%$ & $19.6 \%$ & $4.8 \%$ \\
\hline \multirow{2}{*}{$\begin{array}{l}\text { Benefit of hospice to a SNF } \\
\text { resident* }\end{array}$} & HOSPICE & 4.40 & 0.815 & $0.6 \%$ & $0.6 \%$ & $6.0 \%$ & $16.8 \%$ & $30.5 \%$ \\
\hline & SNF/NH & 3.58 & 1.181 & $3.0 \%$ & $4.8 \%$ & $12.6 \%$ & $13.2 \%$ & $12.0 \%$ \\
\hline \multirow{2}{*}{$\begin{array}{l}\text { Ability to identify hospice } \\
\text { patients* }\end{array}$} & HOSPICE & 3.00 & 1.028 & $3.0 \%$ & $15.7 \%$ & $17.5 \%$ & $14.5 \%$ & $3.6 \%$ \\
\hline & SNF/NH & 3.91 & 0.819 & $0.0 \%$ & $1.8 \%$ & $12.0 \%$ & $20.5 \%$ & $11.4 \%$ \\
\hline \multirow{2}{*}{$\begin{array}{l}\text { Practices in place to provide } \\
\text { special care and/or services } \\
\text { to dying residents/ families* }\end{array}$} & HOSPICE & & & & & & & \\
\hline & SNF/NH & $\begin{array}{l}3.03 \\
3.91\end{array}$ & $\begin{array}{l}1.021 \\
0.909\end{array}$ & $\begin{array}{l}3.6 \% \\
0.0 \%\end{array}$ & $\begin{array}{c}12.1 \% \\
3.0 \%\end{array}$ & $\begin{array}{l}21.1 \% \\
11.4 \%\end{array}$ & $\begin{array}{l}13.3 \% \\
16.9 \%\end{array}$ & $\begin{array}{c}4.2 \% \\
13.3 \%\end{array}$ \\
\hline
\end{tabular}

*denotes significance with $p \leq 0.02$

OT =Occupational Therapy; ST = Speech Therapy; PT = Physical Therapy 